\title{
La Virgen sin cabeza. Vida, lenguaje, territorio
}

FERMíN RODRÍGUEZ Universidad de Buenos Aires - CONICET, Argentina / ferminro0@gmail.com

\section{Resumen}

La vida es la materia inestable de una serie de novelas latinoamericanas del siglo veintiuno que en medio de la crisis ensayaron con nuevos dispositivos espaciotemporales para desmontar las operaciones biopolíticas fundamentales y, en nombre de lo común, sus amalgamas y prácticas aglutinantes, construir otros ordenamientos de cuerpos y sentidos. «Aventura de la materia» — dice la narradora - fuertemente anclada en la materialidad de los cuerpos, La Virgen Cabeza (2009) de Gabriela Cabezón Cámara se interna entre los escombros de la violencia económica y el abandono político para hacer ver a la luz de los nuevos regímenes de marginalidad urbana posibilidades de construir un mundo mejor a partir de la potencia de cambio social que surge del territorio. A diez años de su publicación, La Virgen Cabeza sigue funcionando como un reloj literario y político que adelanta.

Palabras clave: vida precaria / comunidad y territorio / arte y política / literatura y crisis

\section{Headless Virgin. Life, Languaje, Territory}

\section{Abstract}

Life is the unstable matter of a series of Latin American novels of the twenty-first century. In the midst of the crisis, these novels created new space-time devices to disassemble the fundamental biopolitical operations, as well as build others assembles of bodies and senses under the name of the common. Slum Virgin (La Virgen Cabeza, 2009) is an «adventure of the matter» strongly anchored in the materiality of the bodies, through which her author, Gabriela Cabezón Cámara, explores the rubble left by economic violence and political abandonment, in order to show the power of social change that emerges from the territory. Ten years after its publication, Slum Virgin continues to function as a literary and political clock that advances.

Key words: precarious life / community and territory / arts and politics / literature and crisis

Recibido: 9/9/2019. Aceptado: 2/11/2019

Para citar este artículo: Rodríguez, F. (2020). La Virgen sin cabeza. Vida, lenguaje, territorio. El taco en la brea, 11 (diciembre-mayo), 47-66. Santa Fe, Argentina: UNL. DOI: 10.14409/tb.v1i11.9153 
La vida precaria es la materia inestable de una serie de novelas latinoamericanas del siglo veintiuno que a la luz de los nuevos regímenes de marginalidad urbana se dedicaron a montar con lo que tenían a mano nuevos dispositivos espacio-temporales que desvían las operaciones biopolíticas fundamentales y, en nombre de lo común, de sus amalgamas y prácticas aglutinantes, construir otros ordenamientos de cuerpos y sentidos. El diseño de un espacio común, hecho de interacciones entre formas de vida heterogéneas, más que la soledad de una forma sensible separada de la vida, es lo que va a ir orientando la escritura de La Virgen Cabeza, una «aventura de la materia» (LVC:10)' fuertemente anclada en la vulnerabilidad de los cuerpos que se interna a fuerza de encuentros imprevistos en uno de esos potenciales paraísos de esta era que Rebecca Solnit, en su cartografía de las catástrofes, ubica en el infierno. ${ }^{2}$

Por eso, en la villa, que a fuerza de multitud se construye en la novela de Gabriela Cabezón Cámara La Virgen Cabeza, «al infierno nadie le tenía miedo» (LVC:89). Imbuida de la conciencia barroca de que la realidad se escapa como algo que está en continua formación, no menos que del carácter destructivo, jovial y alegre de quien hace escombros de lo existente, políticas de la literatura como las de Cabezón Cámara, con una fuerte marca de desespecificación en sus instrumentos y materiales, ve caminos por todas partes, posibilidades de construir un mundo mejor a partir de momentos de libertad social donde el poder deja de funcionar y se experimenta una nueva distribución de lo posible y lo imposible. ${ }^{3}$

Esto es lo que esta novela, publicada en 2009, vendría a decirnos: que más allá de una visión pesimista de la historia, más allá del colapso social y la crisis económica en la Argentina, más allá de las guerras del capital y el terror económico de la gubernamentalidad neoliberal, hay eso que llamaremos vida - la superabundancia vital de la multitud surgiendo del territorio cuando cae la representación y se abre un nuevo posible; el potencial del trabajo en colaboración que aparece entre los escombros del progreso cuando las partes de una comunidad comienzan a cooperar entre sí.

La historia de la villa El Poso, una experiencia autogestiva con algo de fábula o milagro y mucho de experimento comunitario, es una de las tantas señales de vida que emite la literatura cuando abandona los espacios-territorio nacionales, estabilizados dentro de fronteras por operaciones de producción y reproducción de ciudadanía y autoridad, para darle voz a lo que todavía no existe y revelar a lo largo de un proceso de desterritorialización de la escritura, heterogéneo y múltiple, el carácter potencial de la vida y de la inteligencia de un pueblo por venir. Porque allí donde hay potencia en vías de actualizarse genéricamente (no individualmente), hay siempre muchos reinventándose como cuerpo común, creando sus propias categorías, generando ideas y dándose reglas de asociación y cooperación que son instituciones enteramente políticas.

Efecto de una construcción, de una improvisación colectiva, lo común suele asomarse en momentos inesperados, como emergencia de una en discontinuidad en nuestra experiencia, como apertura de un nuevo campo de lo posible. Esta acción creadora de un desvío o de una bifurcación, presente en muchos movimientos políticos contemporáneos, define también una serie de invenciones artísticas interesadas en las utopías políticas, donde la literatura ensaya con formas precarias de significar y de vivir juntos, con la constitución de pueblos políticos a distancia de las formas estatales del pueblo. Ligada a la producción de nuevos agenciamientos, a la exploración de nuevas posibilidades de vida, la literatura de Gabriela Cabezón Cámara no puede leerse sin ese horizonte de intervenciones estéticas conscientes de que la realización de una utopía 
necesita algo más que la experiencia del arte: con el arte solo no alcanza, pero sin un arte abierto a contextos sociales concretos, que resuene en lo público; sin lo tópico además de lo utópico, todo queda más lejos, todo se hace más difícil de imaginar y de desear.

\section{Milagros}

Inseparables de encuentros e interacciones, de transformaciones y contagios, la vida en tanto "acontecer de la materia» que explora La Virgen Cabeza es sumamente resistente y extremadamente frágil al mismo tiempo, ya que basta con que los colaboradores se dispersen para que se extinga, aunque no sin dejar huellas: el testimonio de lo que produjo, el libro que cuenta la historia del «milagro» comunitario de cuya potencia igualitaria se apropia la escritura. ${ }^{4}$

La novela cuenta, a partir de la indeterminación de cuerpos caídos del relato del progreso, la apertura de una de una comunidad potencial, sin cierre ni exclusiones, basada en disposiciones religiosas, deseos y formas horizontales de solidaridad que señalan, en las periferias del control capitalista, la posibilidad de un nuevo comienzo político, de una nueva forma de vida que no sea ni la del retorno de lo reprimido - los milenarismos que encontramos en el cristianismo, como Canudos en Brasil—, ni la de las pesadillas reificadas de la catástrofe, más allá de las cuales la imaginación política del nuevo milenio no es capaz de aventurarse: como dijo Fredric Jameson, después de la caída del muro de Berlín, es más fácil imaginar el fin del mundo que el fin del capitalismo.

En este sentido, que el cambio se produzca bajo la forma de un ambiguo «milagro», pone la novela en tensión con una experiencia histórica en la que el tiempo se manifiesta como estancamiento y repetición, y el cambio, solo se produce bajo la forma de «accidentes» $\mathrm{y}$ «milagros» —una temporalidad que Jens Andermann, a propósito de la organización narrativa de las películas de Lucrecia Martel, identifica con «la temporalidad propia del "fin de la historia" neoliberal» (2015:256)—. ¿Pero «se puede estar listo para el desastre» (LVC:131), como piensa la narradora de la historia, anticipando el violento desalojo que pone fin al experimento? Algo siempre puede suceder, incluso una catástrofe, pero lo interesante no es el modo en el que un proceso empieza o finaliza: lo interesante es lo que pasa por el medio del devenir, por el territorio, el milieu —esto es, una geografía donde se intersectan producción de espacio y producción de subjetividad de formas inesperadas.

La vida precaria que explora La Virgen Cabeza es una forma de vida incierta, sin expectativas de progreso ni promesas de estabilidad, repleta de accidentes y transformaciones, de umbrales y alianzas, de intensidades presubjetivas y alianzas interespecie, que se define por la fuerza de lo que la mantiene unida tanto como por su amenaza siempre latente de disipación. En este sentido, La Virgen Cabeza es un laboratorio de experimentaciones sociales que, conjugando todo tipo de flujos — semióticos, materiales, sociales—, revela virtualidades desconocidas, habilidades de un pueblo para hacer cosas para las que se suponía que no tenían ninguna capacidad. La literatura trabaja con lo que todavía no existe y le da, en el lenguaje, una cierta realidad a lo posible.

\section{Días de alegre multitud}

¿Qué es lo que se está jugando en estos precarios ensambles de cuerpos que están vivos, con sus deseos y demandas interminables, con sus derechos a la vida y a la persistencia, en los que un grupo de personas afirma su existencia basada en el acto expresivo de ocupar un espacio, hacerse un cuerpo y poner en común? Algo pasó entre los cuerpos, al nivel de su materialidad afectiva, para que allí donde parecía no haber nada —-vida sin categoría, expuesta a la indiferencia, a la violencia 
del barrio, a la represión policial y la violencia soberana-, algo pudiera surgir, un nuevo tipo de lazo, un repertorio de acciones colectivas y de discursos acerca de lo que se desea, capaz de organizar un nuevo territorio existencial relativamente autónomo respecto del estado y del mercado. ${ }^{5}$

¿Y qué es lo que pasa por los cuerpos y desde los cuerpos para que un conjunto multiforme y policlasista de «travestis, paraguayos, pibes chorros, peruanos, evangelistas, bolivianos, ucranianos, porteños, católicos, putas, correntinos, umbandas, cartoneros, santiagueños y todas sus combinaciones posibles» (LVC:72), gente que proviene de horizontes muy diferentes, con diferencias nacionales, profesionales y de identidad sexual, ocupen un mismo espacio y se pongan a actuar conjuntamente de manera de darle una organización espacial a sus necesidades más elementales? Ni la familia, ni la clase, ni las leyes ni la nación sirven para definir ese algo que pasa entre los cuerpos y que en su circulación, les presta un sentido territorial y precario, atado a simbolizaciones igualitarias por la performance de una loca mística que cree y hace creer que la Virgen se le aparece para ayudarla a organizar la villa.

«Algo sagrado circulaba entre nosotros» (LVC:96), recuerda Qüity, la periodista devenida archivista de la vida colectiva, testigo y superviviente de un experimento que tuvo por objeto el carácter potencial de una vida emancipada, en el vivir mismo, de la escisión entre vidas cualificadas, políticamente reconocidas y protegidas, y vida primaria, sin atributos, separada de su forma (que hace las veces de fundamento negativo de una vida normativa). Sólo es feliz, recuerda Giorgio Agamben, aquella vida en la cual desaparece la división entre vidas a proteger y vidas a abandonar; entre vida centrada en formas de ciudadanía y vida aislada de toda comunidad, reducida a población, despojadas de su potencia por una soberanía estatal que se afirma separando la vida de su forma (Agamben:382). Y en esos días «de alegre multitud» carnavalesca, en los que la vida tenía la forma de una «fiesta sostenida» $\mathrm{y}$ «valía la pena vivir» (LVC:89), los personajes de La Virgen Cabeza fueron felices porque «se reconocían como parte de algo» (54) —algo más allá de las identidades que, por debajo de las diferencias individuales, une a los habitantes de la villa a partir de rasgos heterogéneos, preindividuales y asubjetivos, si bien históricos y contingentes, que presuponen la igualdad: el sexo, el lenguaje, el placer, la comida, el calor, el refugio, el dolor, el hambre, el sueño, los afectos, la risa, el miedo, el deseo de seguir viviendo. ${ }^{6}$

La vida precaria es siempre una aventura de la materia, comprometida con una democracia del devenir que se sustrae a las asignaciones del poder. Porque al poder le inquieta menos lo que los individuos son, sus identidades sexuales, étnicas o sociales, que las mezclas, las relaciones de promiscuidad que estos individuos pueden establecer entre sí cuando se encuentran y se modifican mutuamente en el acto de «rescatarse» del lugar que se les asigna en el sistema, cooperando y multiplicando sus posibilidades de vida. Hasta el loco, el marginal o el paria, recuerda Scavino, tienen un lugar dentro de una comunidad orgánica si obedecen a la lógica identitaria del «cada cuerpo en su lugar» (145). ¿Pero qué es lo que un pueblo unido puede cuando se constituye no por semejanzas sino por relaciones reales y vitales de cooperación entre los individuos? La vida de los pibes de la villa, la hermosura de su furia «divina» y su deseo de seguir viviendo no pueden explicarse a partir de individuos aislados; es un «amasijo de nervios, emociones y pensamientos sueltos» (LVC:98), en variación continua, que hay que «hacer hacer» por medios artificiales que oponen el antídoto de la cooperación a la lógica capitalista de la competencia.

$\mathrm{Si}$, desde su centro, la villa irradiaba alegría; si «todos nos reíamos» porque la risa, como materia significante no formada, es el afecto político que arrastra todo el conjunto lejos del miedo, 
la inseguridad y el terror, ¿qué ponemos ahí, en su centro? ¿Ponemos a la Hermana Cleopatra, ex Kleo, ex Carlos Guillermo, la santa travesti portadora del mensaje divino de la Virgen, inventando imágenes y manipulando a los pibes de la villa en nombre de valores espirituales? ¿O ponemos la «fuerza de juntarnos» (LVC:28) invocada por Qüity, la cronista de la historia, enamorada de su «objeto de estudio» (115), que se resiste a creer que sea cosa de la Virgen y no de la fuerza de la unión de los muchos que, basándose en la capacidad de producir de los cuerpos, devienen «alegre multitud» (89), sin una unidad de medida previa? ¿Ponemos la aparición milagrosa de la Virgen, que se comunica con Cleo y le transmite, en un español del Siglo de Oro, mensajes que la ayudan a organizar la villa, o la «aparición» como régimen de hospitalidad y de reciprocidad, según el cual "cualquiera se aparecía en la casa de cualquiera a cualquier hora» y los mensajes pasaban de casilla en casilla por "puertas y ventanas abiertas todo el día» (27-28)? ¿Era la Virgen la que escuchaba las plegarias de los desheredados, 0 «se escuchaban ellos juntos y esa unión era fuerza» (60)? ¿Dónde buscamos las estructuras del poder, en el cielo de la teología política y del carisma, o al ras de las prácticas del territorio, allí donde se hacen y se deshacen los deseos y los afectos colectivos?

\section{En vivo: la tele de los pobres}

Política y teología se cruzan en las performances de Cleo, que en su delirio místico, hace de El Poso una fábrica de visiones y enunciados que giran en torno a la aparición de la Virgen. Pero se trata de un relato para nada ajeno a las estructuras del poder en la tierra, porque este régimen de visión y aparición generalizada es inseparable de los medios y su dispositivo espectacular, que solo se ocupaba de la villa «en caso de desalojos, robos, a veces un asesinato o de vez en cuando el hit de una cumbia» (LVC:149). El monitoreo de las cámaras de seguridad había cambiado «el modo de estar en el mundo» de los habitantes de El Poso (24), objeto de mecanismos de control y disciplinamiento estatal que Cleo disputa según un cálculo que cruza las últimas tecnologías con las tácticas y las tretas del débil: si siempre había querido, como cualquier diva, ser vedette y «aparecer» en una pantalla, salir en vivo ante las cámaras de vigilancia era entonces su oportunidad de poner a circular las imágenes de sus performances devocionales.

Como parte de cualquier teoría de la acción pública y corporal, el espacio es algo más que el soporte de la acción: es el marco de aparición de los cuerpos que, como sistemas de acciones posibles, están donde hay algo que hacer — como decía Merleau-Ponty (265)—. Inseparable de los actos que constituyen su realidad, el cuerpo de Cleo es un cuerpo performativo que, desde su adolescencia, vive de repetir los gestos, los tonos, las formas de moverse y conducirse ante las cámaras de una estrella de la tele, Susana Giménez. Y la propia Virgen, ¿no era «una estrella hace dos mil años» (LVC:24), como lo será Cleopatra cuando la ópera cumbia que Qüity escribió para ella la lance al «firmamento de la fama latina mundial» y otrxs («el hijito trolo y salvadoreño de Madonna») hagan de ella en la película que Hollywood filme con la historia de su vida?

Pero para las cámaras de seguridad que erizan los paredones de la villa, las performance de una Cleo profética haciendo de Susana están contaminadas por el «look Eva Perón» (33) que adopta Cleo, en vivo, para hacer política afectiva en la villa. Evita vive en la teatralidad práctica de Cleo, con el pelo recogido en un rodete y todo el repertorio gestual que inscribe su diferencia sexual en el campo del peronismo y la asistencia social. ${ }^{7}$ Hacer política territorial es básicamente hacer de Evita, dice Javier Auyero en su cartografía de las redes clientelares — una mítica Eva Perón firme y 
abnegada, dispuesta a sacrificarse por sus hijos-. Pero a diferencia de las referentes territoriales del peronismo más tradicional, Cleo no es la madre «pura, virginal y carente de deseo sexual» de la política de los pobres que reconstruye Auyero. Cleo evoca más bien a la Evita del cuento de Néstor Perlongher de 1975 - una Eva lumpenizada, sexualizada y fiestera, salida de las luchas y protestas populares de fines de los 60 y comienzos de los 70. La Eva de Perlongher es una Eva «rubia, un poco con aires de estar muy reventada, recargada de maquillaje, con rodete», que baja del cielo para rodearse de una alegre multitud de putas, locas, drogones y chongos, y anunciar que iba a volver "por este barrio y por todos los barrios para que no les hagan nada a sus descamisados», que en los años 70 no son tanto masa como minorías disidentes. ${ }^{8}$

Como Evita y Susana en la TV, Cleo vive y sale en vivo en las cámaras de seguridad —la «tele de los pobres» (LVC:34)—. Pero La Virgen Cabeza opera un proceso distinto a la TV y a su sistema unilateral de transmisión de imágenes y palabras que va de un punto concentrado de emisión hasta una multiplicidad de receptores tomados, uno por uno, por un cierto léxico, una cadencia, un ritmo enunciativo, una modulación del afecto que remite a formas de subjetividad estándar. ${ }^{9}$ Nada une a esa composición colectiva, ningún lazo de amistad o cooperación, ningún devenir común. La novela de Qûity y de Cleo, en cambio, se juega en la relación dialógica de apropiación de la palabra ajena, que es siempre un mundo posible más que un intercambio lingüístico. ${ }^{10}$ Sus enunciados son colectivos, en tanto confluyen con el rumor anónimo de una multiplicidad de voces de donde extraen su propia voz. «Cada uno articulaba lo que quería decir en sintaxis propia» - recuerda Qüity— «y así armamos una lengua cumbianchera que fue contando la historia de todos» en una nueva sintaxis que tiende a una forma agramatical (27)."

Cleo graba su versión y le pide a Qüity que, en nombre de su «derecho a hacerme escuchar» (LVC:25), incluya en la historia su verdad, aunque compartan memorias y, como reconoce la propia Cleo, «ya no sé ni pensar en mí sin hablar con vos» (24). Qüity, por su lado, se queja de las intervenciones constantes de Cleo, y quiere dedicarse en el futuro a la ficción porque «no se puede escribir la propia biografía con una esposa que se considera coautora, salvo que sea otra escritora» (153). Tal vez Cleo no sea una escritora, pero sus performance místicas, que no pasan por una obra pero sí por una serie de conductas e intervenciones que se efectúan en la vida misma, ¿no forman parte de una práctica que, aunque no se despliegue por los medios tradicionales del libro, produce efectos que, en su indeterminación, ponen en juego modos de hacer e instrumentos que provienen de la performance, orientados a la invención artística de un pueblo? ${ }^{\text {12 }}$

\section{Territorios en trance}

El rostro se metamorfosea, el cuerpo entero se transforma, poseído por un agenciamiento colectivo que lo atraviesa y lo hace hablar en la lengua epifánica del trance como inflexión del mito. «El trance, la puesta en trance, es una transición, un pasaje, o un devenir: es el trance el que posibilita el acto de habla", dice Deleuze, que trae los estudios clásicos de Roger Bastide sobre el candomblé bahiano para analizar en el Cinema Nôvo de Glauber Rocha la producción de enunciados colectivos que contribuyen a la invención de uno de esos pueblos por venir de las literaturas y las artes menores. ${ }^{13}$ Cleo tiene algo de médium, hablada por un discurso libre indirecto que la atraviesa de punta a punta donde se mezclan de manera promiscua visiones y enunciados heterogéneos, pasajes de la Biblia, oraciones de iglesia, fragmentos de textos literarios, versos de la literatura clásica y medieval, canciones populares. 
«¿De dónde mierda sacaba cosas como esa? ¿Existirá la Virgen y le dará por los clásicos y las putas pobres?» — se pregunta Qüity, que no puede entender cómo Cleo podía citar la Odisea casi letra a letra (LVC:17)—. Pasiones y saberes se acumulan en torno a Cleo, fragmentos del discurso amoroso agenciados por un dispositivo colectivo de enunciación que lo procesa todo para crear sentidos nuevos por medio de conexiones. En Cleo convergen las lecciones del padre Julio antes de ser el Obispo, un cura abusador que además de cogerse a Cleo cuando tenía 13 años le enseñó «las cosas de Dios y a leer bien y me mandó a la escuela nocturna» - 59-); las charlas con Daniel, el funcionario de la SIDE compañero de Qüity, ex estudiante de Letras, que recita para Cleo los clásicos («Daniel y Cleopatra podían charlar horas, siempre encontraban qué decirse» -73-), más eso de que «los hermanos sean unidos porque esa es la ley primera», que en la Argentina «lo saben hasta los analfabetos» (6o).

Todo ocurre siempre entre por lo menos dos términos —Cleo y el padre Julio, Cleo y Daniel, Cleo y Qüity—, que no son sujetos sino agentes, elementos de un dispositivo maquínico de enunciación que acopla cuerpos y enunciados y que es lo que nos hace hablar. Así, sin las voces, las imágenes y los signos que transmite Cleo no hay aventuras de la materia, en tanto el lenguaje es el medio por el cual adviene el acontecimiento y se expresa la vida como deseo. La Virgen Cabeza es una máquina barroca de hacer delirar la lengua. ${ }^{14} \mathrm{Y}$ su barroquismo es un procedimiento de desarreglo del sentido que anula las jerarquías y lo mezcla todo, tensando la oposición que atribuye a los pobres como Cleopatra «la lucha por los lazos comunitarios y contra la miseria», mientras que «el deseo individualista de creatividad autónoma» es un asunto exclusivo de los hijos e hijas rebeldes de la burguesía, como Carolina Sánchez Qüit, antes de hacerse villera y pasar a llamarse Qüity (Rancière:39). ${ }^{15}$ Qüity, que lleva la fuga en el nombre, se enamoró de su objeto de estudio («me calenté con mi objeto», dice — LVC:115一), corriendo detrás de Cleo con el grabador para que le hablara de la Virgen, y Cleo «empezó a morir por mi deseo de sus palabras» (115). ${ }^{16}$

\section{Los pibes y el chorro}

No hay una comunidad en tanto unidad o conjunto homogéneo de individuos compartiendo un mismo rasgo, sino la unidad real y vital que forman los cuerpos que hablan y trabajan al colaborar entre sí en tiempos precarios, la interacción entre las personas e incluso sus vínculos con otras especies y con las cosas, el aire, el agua, la tierra, la luz. No es entonces la lógica de la dominación religiosa, manipulando la palabra, implantándose despóticamente desde arriba, lo que une a los cuerpos de la villa. Tampoco se trata de un público, el modo de subjetivación de las democracias de mercado y sus máquinas de construir mayorías a través de los medios y sus dispositivos fascistas de centralización lingüística. ${ }^{17}$

Hay que dejar de pensar el poder desde arriba. Ni la Virgen ni la pantalla de la tele: en el medio de la villa, surgiendo de lo profundo de un pozo como punto de fractura de una totalidad social, estaba, incontenible, el chorro, el chorro, que los pibes chorros ven elevarse de las entrañas de la tierra como un géiser. Quebrando el tejido de «huesos, raíces, muertos y gusanos» (LVC:69), el chorro reventó la superficie del suelo e inundó los terrenos bajos y arcillosos de la villa, hasta formar un estanque que los habitantes aprovecharían para hacer icticultura, «que es como la agricultura pero con pescados», explica la Virgen (66).

Sin insistir en el dogma, Cleo traduce el milagro de la multiplicación de los panes y los peces a imágenes bien concretas que reducen la religión a un núcleo de preceptos básicos. La Virgen le 
dirá entonces a Cleo que tenían que ser pisicultores, construir un estanque en el medio de la villa y sembrarlo de carpas para que se reprodujeran y así poder alimentarse. Se trata de una religiosidad práctica, alejada de la interpretación pasiva de las escrituras ( $Y Y$ todo tenía que ser como estaba escrito, me explicó» —66-), que Cleo lee en la clave terrenal, puramente moral y política, de los materialismos populares. ${ }^{18}$

Hablar y comer: en tiempos de bocas abiertas y agenciamientos polifónicos, la Virgen le mete la lengua hasta la garganta, le introduce a Cleo la palabra "carpa» en la boca - esa «manducación de la palabra, semifagia de una nueva forma» que Deleuze y Guattari le atribuyen al «delirio de acción» de los profetas-. ${ }^{19}$ Acontecimiento de la materia, surgido de la nada por un repertorio de acciones colectivas, cada cosa empezó a parecer parte de un plan, «algo con sentido y objetivos» (LVC:86), un hacer y un hacerse vivir en batalla contra la precariedad, creador de una realidad nueva.

Nudo de tejido comunitario, la fuerza relacional del estanque comienza a ordenar el reino en miniatura de la villa — un pequeño remolino de vida que se forma dentro de la multiplicidad del tiempo y de la historia - Las aventuras de la materia son las aventuras de un paisaje fracturado que se organiza alrededor de ese espejo de agua turbia donde en apenas un verano, las veinte carpas multicolores sacadas del Parque Japonés se vuelven mil doscientas. La miseria empezó a ser austeridad; la deprivación, práctica de la no-propiedad y gestión de lo común, identificada con una forma de plenitud y abundancia: en la economía barroca de la villa, articuladora de dinámicas sociales veloces y desbordantes, comida no le faltaba a nadie. Se comía carpas «en guiso, con chimichurri, en chop suey, en puchero, con salsa agridulce, en salpicón, saltada con verduras, con polenta, en ceviche y, obvio, asada» (LVC:81), y todo en los interminables almuerzos y cenas comunitarias era para todos. Sin buscar el beneficio personal, la comunidad no renuncia al progreso, según una suerte de emprendimiento de masas que se afirma pragmáticamente en un conjunto de tácticas que vienen desde abajo. ${ }^{20}$

Estamos en un mundo de bocas bien abiertas, llenas de materias expresivas disonantes y rumores a-significantes — «los crujidos, degluciones y quebraduras» con que el mundo paladea y se come al mundo (LVC:109) - Alimentadas con los restos de los banquetes, las carpas tragaban todo lo que se les cruzaba por delante de sus bocas recicladoras. «A los pescados», predica Cleo, «los metés en el agua, les tirás comida y ellos se reproducen» (66). Lo mismo ocurre con los demás bichos que formaban la ecología de la villa, repartiéndose por altura los restos caídos del cielo de los banquetes. Gatos, pájaros, perros, caballos y ratas viven juntos, sin armonía ni conquista, en un agenciamiento, un encadenamiento interespecies de humanos y no-humano donde la simbiosis es la regla y nada de lo que ocurre — porque la vida es del orden del encuentro-acontecimientose afirma en forma aislada. ${ }^{21}$

\section{Todos con todos}

Pero en el medio de la abundancia reproductiva, no todo era una simple cadena alimentaria, no todo era un «morder, masticar, tragar» (LVC:109) y reproducirse de cuerpos reunidos en nombre de que están vivos, capaces de manejar colectivamente la precariedad impuesta sobre la base de condiciones comunes más que a la identidad. En intersección con el animal, el «pueblo» de la villa quiere lo mismo que quieren los pueblos que se rebelan en nombre del cuerpo que está vivo: que le den de comer y, más allá de la mera reproducción de la especie, que le den de coger. ${ }^{22}$

Irrigado por el chorro, el campo biopolítico que se despliega en la villa se inunda de deseos y creaciones cuya dinámica excede las estrategias de control espacial del poder. Se trata de un 
espacio producido colectivamente donde lo común, siguiendo a Negri y Hardt (134), nombra a la vez un medio de producción, un modo de hacer y una forma de vida. A las políticas que dictan violentamente, de arriba hacia abajo, quién y cómo puede gozar, los comuneros de la villa le oponen otra espacialización de un deseo no mercantilizado - un arreglo donde todo era posible y cada cosa que vive, con su ritmo, se encuentra «siempre arriba, abajo, adentro y al costado de otra» (LVC:111), multiplicando sus conexiones en arreglos inestables-. En el «barroco miserable» de la villa, el espacio se da bajo la forma de relaciones de proximidad y superposición, donde cabe todo y nada parece excluir una cosa de otra. El mundo se acababa y «todo cogía con todo» (111) en interminables fiestas - meseta de intensidad donde se hacen los cuerpos, que por encima del frenesí reproductivo de las carpas y la satisfacción de sus necesidades vitales, se dedican "casi exclusivamente al placer» del sexo sin reproducción (81).23

«Nos desbordábamos, no podíamos contenernos» (LVC:107), recuerda Qüity, sujeta al deseo más que a la necesidad, mientras se entregaba al puro gasto de las fiestas donde fue convirtiéndose en letrista encargada de dar, en poco sutiles cumbias, un sentido impuro y polifónico a las palabras de la tribu. De la excepción al exceso, al desborde y al «frenesí rítmico» del goce festivo, lo que pasa en La Virgen Cabeza es del orden de la sexualidad, no porque estemos en el reino de la transgresión, como señala Gabriel Giorgi a propósito de la ópera El Fiord en la puesta de Silvio Lang (2017), no muy lejos de la estética de Cabezón Cámara, sino porque la sexualidad es «el terreno en que se forjan, se hacen y se deshacen, los afectos y los deseos colectivos, donde se tensan sus inscripciones en lo público, y fundamentalmente donde se registran las formas en que se inscriben los cuerpos bajo la luz de sus deseos, sus alianzas y sus guerras, esto es, sus políticas» (Giorgi:45).

Por eso, «que yo haya sido o no un macho no es el principio de nada», se queja Cleo por el orden que Qüity pretende darle a la crónica (LVC:22). ${ }^{24}$ Cleo es una travesti que ejerció la prostitución, que es pobre, que sufrió el castigo de su padre ex sargento de policía por ser «un puto del orto» que quería parecerse a Susana (34), pero que, como líder comunitaria, ya no necesita decir «soy travesti» y hablar por su identidad sexual, porque ahora, en el medio de la villa, el problema del «origen», de ser o no ser una mujer, no le importa a nadie. Del travestismo, comenta la propia Cabezón Cámara en una entrevista, Cleopatra tiene «la gracia, el humor, algunos gustos por determinada clase de ropa, pero lo preponderante en ella es que es una líder villera. No necesita decir "soy travesti" (...). No padece discriminación", así que no tiene por qué defender una identidad sexual que cabe perfectamente en la heterogeneidad de un mundo que crece por contagio, difusión y resonancia de series.

Lo que pasa por la boca de Cleo, la sintaxis de sus acciones proféticas, constituye la realidad de lo posible surgiendo desde los cuerpos y sus circuitos de interdependencia, no desde la identidad. ¿Y qué decir de los «trances» de Qüity, que se va convirtiendo en letrista de cumbia en medio del desborde de las fiestas, tomada por el «frenesí rítmico» (LVC:107) de la música y el baile? «Los vivos charlábamos en grupitos marcando el ritmo de la cumbia de fondo» (43), dice Qüity, que en un principio se resiste a «la estupidez de las letras» (113) recitándose cancioneros antiguos a modo de conjuro, «para no perder el lenguaje» (114). Pero el ritmo del reggaetón «se me metía en el cuerpo y en el lexicón de la mente cerebro» para hacer tartamudear la lengua y arrastrar la copla («Bailemos las tres, amigas queridas,/ bajo estas avellanas floridas») hacia nuevas ramificaciones, siguiendo una línea de fuga que desorganiza las formas y pone la lengua en variación («Chupemos las tres, amigas queridas/ de estas conchudas heridas»). Las fiestas en las que Qüity se vuelve 
letrista la ponen fuera de sí, alejándola de la palabra oficial que, en su inflexión periodística, hubiera reducido lo sagrado del «trance místico» a un sórdido asunto de drogas y alcohol (108). ${ }^{25}$

\section{Los de abajo}

Frontera turbulenta e inestable entre comer y hablar, entre palabras y alimentos, entre la boca y la lengua, entre la reproducción y el deseo, entre el ruido y el ritmo emputecedor del reggaetón, las fiestas de El Poso son una zona de indeterminación humano-animal donde se borran las diferencias sociales e interespecie y los habitantes quedan igualados por rasgos preindividuales que circulan por debajo de sujetos que entienden, a partir del cuerpo y sus afectos, que su vida y su subjetividad son producto de la cooperación social y el vivir juntos.

La proliferación de límites reorganiza el espacio, que toma formas inesperadas. La desdiferenciación, como corriente de afectos no formados no solo pasa por debajo de la frontera humanoanimal: también establece cierta igualdad entre vivos y muertos. El chorro era también «una fiesta de basura antigua y arqueología contemporánea» (LVC:69) que trae hasta la superficie reliquias históricas según un arco que va de principios del siglo XIX hasta fines del XX y comienzos del XXI (69), sin rastros de lo que hubo en el medio; la villa «no se hacía con las mismas cosas que el Taj Mahal», objeta Cleo (70) y no hay ruinas de la miseria porque por un lado, en ella todo «se pudre, se quema y se vuela» (70), y, por otro, en su multiplicidad fracturada, el espacio sensorial de la villa se produce, se destruye y se rehace con lo que Gastón Gordillo, para no hablar abstractamente de ruinas, propone llamar lisa y llanamente escombros ${ }^{26}$ —acumulaciones de materia sin forma, desfetichizada y cargada de tensiones, que el chorro escupe y que los habitantes del lugar defienden de su patrimonialización por parte de los arqueólogos que «entraron pisando fuerte para llevarse lo que creían propio» pero que entendieron enseguida, apenas se lo insinuaron, que «cualquier cosa que encontraran era nuestra» (70).

Nada desaparece sin dejar rastros, nos recuerda el chorro, que trae desde el fondo de la historia la materialidad obstinada y perturbadora de los huesos de los muertos: «Teníamos muertos de tierra adentro y de tierra afuera, muertos de todos los colores, muertos mutilados de la última dictadura, muertos armenios del genocidio que no recuerda nadie, muertos de hambre de los últimos gobiernos democráticos, muertos negros de Ruanda, muertos blancos de cuando la revolución de San Petersburgo, muertos rojos de todas las revoluciones de todas partes, hasta un diente de Espartaco encontramos, muertos unitarios con una mazorca en el orto, y muertos indios sin orejas» (LVC:72-73). ¿Y la cosecha de muertos de El Poso, producto de formas de destrucción que continúan en el presente? Los huesos de las chicas que se resisten a la trata o los huesitos de Kevin, el niño que adopta Qüity y que va a asesinar la policía cuando llegue el desalojo, «haciéndose suelo de cementerio... humus, pampa húmeda» y, con el tiempo y las raíces y las fotosíntesis, «aire, agua, tormenta» (13). La imagen del cadáver como naturaleza en decadencia, descomponiéndose en sus partes blandas hasta volverse materia inorgánica (en la villa «todo se pudre, se quema y se vuela»), revela la violencia infligida sobre los cuerpos. Pero los huesos no desaparecen: los huesos, como dice Gordillo, son escombros de los cuerpos, «restos materiales que no se han disuelto completamente en la nada» y que, en su dureza, «encarnan la persistencia del cuerpo a largo plazo» (272).

La producción de subjetividad no pasaría tanto por una toma de conciencia como de la lenta transformación biopolítica de un ser social que, capa sobre capa, se acumula de manera sedimentaria sobre el suelo barroso de la villa. Estamos frente a una noción expandida de sociedad que 
incluye no solo a los vivos, sino también a los muertos - muertos de una historia de odio y de violencia política acumulada en capas y capas geológicas de derrotas revolucionarias y resistencias aplastadas por las guerras de clase, de raza y de sexo que, hoy como doscientos años, están en la base de un capitalismo que profundiza las desigualdades por medio de técnicas de división y segregación.

Hacia abajo y desde abajo, la noción de comunidad se amplía para darle cabida a los muertos, cuya capacidad de afectar a los vivos va incluso más allá de la negatividad de la presencia física de los huesos. En tanto ser social sedimentado, los restos son algo más que una mera figura de la negatividad porque irradian a su alrededor una espacialidad colectiva amenazante que conecta transversalmente huesos e insurrecciones.

Si en las tierras bajas de El Poso «la pirámide social se hace geografía» (LVC:51) porque el agua de las precipitaciones inunda, en primer lugar, a los de abajo, la erupción del chorro introduce una temporalidad diferente. De la negatividad pasamos al poder de afirmación de los huesos y los restos como fuerza vital potencialmente disruptiva, inseparable de prácticas de afirmación de la vida en su vulnerabilidad, pero también con su potencia de ruptura.

\section{Los de arriba}

Los huesos que remueven La Virgen Cabeza no solo ponen al descubierto nuestro carácter precario como individuos, sino también la injusticia y la violencia asesina de la economía de mercado, comenzando por la propiedad de la tierra. Esas constelaciones de huesos que afloran a la superficie pasados los años señalan la "naturaleza cársica» de una serie de movimientos políticos generadores de prácticas y subjetividades que, como las aguas que circulan por napas subterráneos, ascienden de vez en cuando como un géiser para interrumpir desde abajo el orden existente y abrir túneles secretos que conectan la resistencia contra las especulaciones inmobiliarias con las contiendas coloniales y modernas por la tierra (Negri y Hardt:67).

Por cinco generaciones, los pobladores de la villa hicieron lo mismo que millones de marginados urbanos en todo el mundo: crear su propio espacio a partir de formas de vida que no solo ocupan sino que constituyen el territorio a partir de relaciones sociales diferentes. ${ }^{27}$ Sin embargo, cinco generaciones viviendo en un mismo terreno no son un título de propiedad suficiente para los habitantes de El Poso, barridos del mapa por el «tsunami inmobiliario» (LVC:132) que se abate violentamente sobre una comunidad que entra en abierto conflicto con el capital cuando se niega a cumplir con una orden del juzgado de desalojar la villa y mudarse a un complejo de viviendas sociales en tierras baldías de La Matanza, sin estanque ni lugar para la Virgen.

Desde lo alto, el ojo del poder se había posado sobre ellos, no porque existiera una instancia divina habitando por encima de El Poso. Las formas dominantes del poder son de este mundo, y desde sus helicópteros celestiales, miran la villa desde las alturas como los villeros miran a las carpas del estanque (LVC:95). Diariamente, por encima de El Poso, vuela el helicóptero del Jefe, el hombre de negocios al frente de la especulación inmobiliaria que da la orden de «despejar» la villa (151). En uno de sus vuelos periódicos, había visto la villa «desde arriba, vio las casillas con los techos florecidos de malvones, el hacinamiento, vio a las vírgenes y a los santos, vio la vecindad con las mansiones de sus socios y pensó que los villeros no merecían vivir así, que sus amigos no merecían semejante contigüidad y que esos terrenos merecían una buena renta» (149-150). «Soy la cabeza, pienso los negocios, negocio con las otras cabezas» (151), confiesa el Jefe, la auténtica «cabeza» 
de la historia, el verdadero enemigo. Las formas dominantes de poder, la violencia asesina de la economía de mercado y sus gendarmes, son de este mundo, y una vez que descartamos las pretensiones teológicas, reconocemos sus estructuras en la tierra, hundiéndose en la realidad política, social e histórica del territorio para apropiarse de lo común.

\section{Las armas enloquecen}

¿Se puede dejar de pensar el poder desde arriba, ignorando la confrontación y la guerra de clases? ¿Alcanzan las acciones performativas y discursivas de Cleo y Qüity para enfrentarse con la violencia del capital y sus derivas fascistas? ¿Basta con hacer reconocer la diversidad de sujetos humanos y no humanos, instalada en el reino en miniatura de la villa, para tener el mal a raya? ${ }^{28}$

A Qüity no le entra en la cabeza que los hubieran matado por negocios; que la única vida que estuvo en juego hubiera sido la vida del capital —un capital que gobierna succionando la superabundancia vital de la multitud para devolverla convertida en muerte- - La guerra contra las poblaciones es la verdad de una biopolítica que amontona a los pobres en la villa para abatirse sobre ellos como una fuerza que se imagina a sí misma como natural, como la ley de gravedad o de selección natural de una fortuna que justifica cualquier cosa que la agrande un poco más. Pero «no es cuestión de fortuna, es cuestión de fuerza» (LVC:151), entiende Qüity cuando es demasiado tarde, pasando de una crítica del poder centrada en lo sagrado de la vida («yo también debía creer... que en la vida había algo de lo sagrado» -151—) a una crítica «nietzscheana» del poder en términos de relaciones de fuerza y voluntad de poder.

Qüity encabezaba la comisión de comunicación de la villa porque «era de los pocos que tenía cierto dominio sobre el lenguaje» (LVC:133) y, desde allí, era la encargada de discutir «democráticamente» con las campañas de terror de los medios contra los pibes de la villa y de interpelar al poder político en nombre de un «derecho a vivir» en el que se escucha algún eco del discurso de los derechos humanos (93). Como periodista, participa de la esfera pública, y su horizonte de referencia era el de la ciudadanía. Pero el conflicto no era solo intradiscursivo: estaban en guerra. Y Cleo lo intuía. En medio de sus rutinas pastoral-comunitarias, Cleo sabía (se lo dijo la Virgen) que «siempre estamos en guerra» (91), y no se olvida que incluso en los mejores días de la pequeña comunidad democrática, cuando parecía que el diseño de una sociedad mejor era posible y viable, la policía no dejaba de asesinarlos. «Mi amor, te olvidás de todo, vos» —le reprocha Cleo- «Porque nos tiraban por negros, por pobres, por putos, por machos, porque nos cogían o porque no nos cogían; qué sé yo por qué: a lo mejor practicaban para la guerra» (93).

Pero no era un entrenamiento para la guerra: estaban en guerra —una de esas guerras asimétricas por el control de la población contra meros sujetos "peligrosos», sin «enemigos» propiamente dichos, donde los lugares de vencedor y de vencido se encuentra previamente asignados y estabilizados a favor del capital - La especulación inmobiliaria es una máquina de guerra montada con una serie de piezas heterogéneas (políticas, jurídicas, económicas, tecnológicas, institucionales), dispuestas estratégicamente para el ataque y la conquista del territorio del otro. Con y sin la Virgen, Cleo y Qüity entienden que en la democracia neoliberal no hay sino economía, información, religión y leyes de guerra, en tanto en todos estos campos, como dice Rozitchner, «sigue predominando no la justicia sino el poder asesino del "más fuerte”» (420).

En cualquier caso, sin visión «estratégica» de la lucha contra la violencia social, racial y sexual del capital, ni Cleo ni Qüity estaban listas, en su pacifismo, para lo peor, que se les vino encima 
cuando las topadoras y los bulldozer, en medio de los tiros de las fuerzas de asalto, aplastaron a los pobladores y redujeron la villa a pilas de escombros que servirían de cimiento para el futuro country.

Guiado por la sed de ganancias, por la venganza y el odio de clase, el magnate al frente de la especulación inmobiliaria sabía que nadie entrega su tierra sin resistencia. Cleo y Qüity, en cambio, no. Estaban dedicadas a construir en el aquí y el ahora de la comunidad un poder diferente al del terror armado, hecho de cuerpos y no de hierros - cuerpos capaces de apropiarse de un territorio, de organizarse y producir una nueva forma de vida basada en lo común-. ¿Deberían entonces haberse armado y trocado en una fuerza armada, preparada para lo peor? ¿Deberían haberse organizado como guerrilla, con la toma del poder en el horizonte? ¿Deberían haber abjurado de la Virgen o rechazado el liderazgo carismático de Cleo, para practicar una horizontalidad a ultranza, sin confiarse a ninguna forma de trascendencia? Las armas enloquecen, y de haberse militarizado, ¿no hubieran dejado de ser lo que eran, a saber, una multitud libre y alegre, reunida por el deseo común de seguir viviendo? Sin armas ni «fierros» mediáticos, los villeros, en su multiplicidad, trataron de resistirse al desalojo. Organización no les faltaba, pero la fuerza de su solidaridad -el único poder con el que cuentan los que no tienen otros bienes - no bastó para evitar que fueran dispersados y dejaran de existir, porque la vida no existe cuando los lazos de la comunidad son cortados y los individuos, desolados en su derrota, son llevados a actuar por separado.

\section{El fin de la historia}

El sueño de un mundo compartido, donde no importa quién es quién porque la identificación cedió lugar a la participación y a la cooperación, no termina bien. Pero puede que no haya final feliz para las historias que no están hechas desde la imaginación del progreso y la modernización, cuando pensábamos, dentro del marco de las filosofías de la historia, que las cosas iban colectivamente hacia algún lado.

De hecho, la historia comienza con Qüity desolada en el Tigre, meses después del desalojo, literalmente aislada, donde espera para salir del país en compañía de Cleo (y de la cabeza de la Virgen, que también sobrevivió a la masacre) y huir clandestinamente a Miami. Con la carga de haber sobrevivido al desalojo y a la masacre que terminó con la vida de 183 pobladores de El Poso, Qüity es un «cementerio de muertos queridos» (LVC:16), comenzando por Kevin, el niño baleado por los gendarmes que la había adoptado como madre. La muerte de Kevin no deja de repetirse en Qüity, tomada de punta a punta por el duelo y la melancolía. ${ }^{29}$ La historia de la villa se repite en su memoria como decadencia y sucesión de escombros, como un «collage de desperdicios» (9) arrastrados por la corriente de un pensamiento que es también una meditación barroca sobre la decadencia de los relatos orgánicos - totalidades de sentido donde los hechos se sucedían unos a otros según la lógica narrativa del principio, el desarrollo y el final.

Pero las aventuras de la materia continúan: mientras Kevin se vuelve «amasijo de huesos y gusanos» revolviéndose en las entrañas de la tierra donde se convierte en "suelo de cementerio» (LVC:12-13), la hija de Cleo y Qüity —unidas como amantes después del desastre— late en las entrañas de Qüity, porque la muerte no es la finalidad de la vida y «este ser de la materia que soy», dice Qüity, se aferra a la vida y persiste en su ser, en «su voluntad de seguir siendo» (14).

Así termina la historia de El Poso en la versión de Qüity, "con un asesinato y un polvo», como resume con acidez Cleo (LVC:153), sin incluir la deriva villera que las llevará de los gusanos del 
cementerio de Boulogne a los gusanos de la playas de Miami, nostálgicos de la Cuba capitalista de antes de la Revolución, convertidos por Cleo a la fe de la Virgen. Todos conocen la historia, ¿para qué volver a contarla?, se justifica Qüity, que decide dedicarse de allí en más a la ficción porque después de la experiencia fallida de El Poso, «no me puedo juntar más» (28) y se cansó de las objeciones de Cleo y sus pretensiones de coautoría en nombre del derecho de las clases populares de hacerse escuchar. Escritura y oralidad se divorcian, porque «no se puede escribir la propia biografía con una esposa que se considera coautora, salvo que sea otra escritora» (153).

«Todo lo que is born se muere», cantará Cleopatra, con voz de afirmación, humor y originalidad en la ópera cumbia compuesta por Qüity, que lanzará la historia «al firmamento de la fama latina mundial» LVC: (24). En otro lugar, otra lengua y otro género, la historia y la alianza continuarán. Perreando y proyectando los poderosos mensajes sensoriales de la Virgen ante multitudes devotas de gringos convertidos (27), Cleo conseguirá como estrella de la música latina lo que a nivel local, como activista y líder comunitaria, no había logrado: trascender con su imagen y con su voz profética los límites de la sociedad en miniatura de la villa; convertir a quinientos mil gringos a la fe marianista y hacer que la «lengua cumbianchera» y colectiva que habían armado entre todos resuene en una escala social más amplia, circulando por los programas de tele, las revistas, los diarios y los sitios de Internet de la industria cultural global.

¿La historia termina así, con Cleopatra y Qüity apropiándose privadamente de lo común para convertirse en «dos señoras ricas del primer mundo» entregadas al consumo (LVC:20), reterritorializadas entre las paredes de una mansión amurallada que remeda obscenamente, con su búnker, su gallinero, su huerta y su nuevo estanque, las prácticas colectivas de El Poso? ¡De ninguna manera! Cleo asegura que «la fama y la guita vienen de la Virgen y por la Virgen y para la Virgen» (154), cuya orden es ahora construir, con los diez millones de dólares que ganaron con la cumbia, una catedral ambulante que les permita aprovechar el liderazgo mediático de Cleo y difundir el mensaje marianista por el Caribe, comenzando por una Cuba que en los vaticinios de Cleo, no va a lograr sobrevivir a la muerte de Fidel.

A diferencia de los carritos de los cartoneros de La villa, modernos y funcionales, el altar móvil de la Virgen Cabeza es un monumento portátil del barroco americano, un «adefesio carísimo y estrafalario» (LVC:159) que Cleo diseña con la ayuda de los joyeros de Rolex (los joyeros del «lujo eterno»). En la lógica del derroche y del gasto improductivo, la cabeza de cemento pintado que sobrevivió a la masacre queda revestida de gemas y materiales suntuosos: cabellera de oro y plata, dientes de diamantes, labios de rubíes, ojos de zafiros, piel suave y tersa confeccionada artificialmente, y todo cubierto por una caja de cristal blindado, con cámaras que graban alrededor y minialtavoces por los que una computadora programada en loop pasa cumbias y reza el avemaría. Ensamblando cuerpos, mensajes y signos religiosos, piedras preciosas, nuevas tecnologías reproductivas y materiales de la cultura de masas, conectada e integrada a otras máquinas sociales, la catedral portátil multiplicará el agenciamiento maquínico de enunciación de la Virgen por el Caribe, orientado a la producción de una subjetividad que solo va a surgir del actuar-con y crear-con de la cooperación social.

Sin creación de agenciamientos maquínicos propios que conjuguen dinámicas culturales heterogéneas, lenguajes innovadores, sensibilidades afectivas y relaciones sociales alternativas, las posibilidades de una isla comunitaria como medio de la igualdad son escasas — una isla donde la precariedad represente un potencial más que una privación y los náufragos puedan sobrevivir trabajando como lo hizo Robinson Crusoe, solo que de manera colectiva en vez de individual一. 
La relación de fuerzas entre el socialismo y el capitalismo es ahora totalmente asimétrica; las pocas chances que una pequeña comunidad de iguales como la de El Poso tiene de sobrevivir y organizarse de forma autónoma en medio de relaciones capitalista, recuerda a las contradicciones y dificultades que implica mantener, después de la caída del muro, el socialismo en un solo país, comercial y financieramente aislado.

\section{La Virgen sin Cabeza}

La historia continuará en una Cuba estragada por el bloqueo económico y la apropiación burocrática de lo común, cercada por una máquina de guerra capitalista agresiva y triunfante. Fidel y su liderazgo carismático no durarán por siempre, y la derrota de la revolución es una catástrofe social en cámara lenta que no deja de ocurrir.

En contrapunto con la pulsión de muerte que anida en Qüity y en abierto desafío a su sentido del final, Cleopatra se irá con la Virgen y con la música a otra parte a hacer política, esto es, a conseguir cosas y hacer que determinadas cosas pasen bajo la forma de la multitud, poniendo énfasis en las redes, las relaciones y los vínculos personales. Como quedó demostrado, talentos para la cooperación social no le faltan, ni para hacer espacio a partir de la resonancia festiva de sus performances milagrosas - espacio no solo como lugar a ocupar sino como creación políticocultural, generador de procesos y luchas sociales-. Náufraga de un violento sistema que precariza, explota, margina y reprime brutalmente, probablemente reconozca, peregrinando por Cuba, que en el socialismo la vida de los más pobres y los oprimidos no es peor que en la democracia de mercado de la que apenas logró salir con vida, no sin haber aprendido la dura lección de que no hay proyecto de transformación social sin una organización política viable y duradera con base en una democracia de lo común - una democracia abierta y expansiva de la cooperación y la interdependencia, que sirva de antídoto tanto para la lógica capitalista de la competencia individual como para la lógica productivista impuesta desde lo alto por un partido único que en nombre de la dirección de la sociedad asume un férreo control disciplinario de la población.

La revolución política y social de los años 6o, en plena Guerra Fría, con su partido revolucionario único y sus promesas de futuro, renunció a la satisfacción de las necesidades básicas (y no tan básicas) en un mundo donde la utopía de una sociedad sin clases se disuelve en el cuerpo viviente de una población reducida a función económica programable por parte de un Estado-Partido que, basándose en una ética del sacrificio, predicó la renuncia a la satisfacción inmediata de las necesidades como cura de todos los males sociales (Dardot y Laval:73).

En este sentido, la forma estado-partido, con su dirección vertical de la sociedad, su producción de subjetividad —el «hombre nuevo»—y su poder molarizante de «homogeneizar» el deseo, va a entrar en tensión con la toma de partido por la Virgen y la creencia popular en el poder de sus milagros, inseparables de la satisfacción aquí y ahora de necesidades vitales no menos que de deseos que dependen de los modos que tiene una comunidad de hacer las cosas, «ya que al producirlas de determinada manera» —explica Scavino siguiendo a Marx—, «produce, también, a sus consumidores» (56). El deseo es siempre grupal, deseamos lo que los otros desean.

Cargada de energías deseantes, la máquina milagrosa que empuja Cleo se desplaza haciendo delirar la lengua, si por delirio entendemos menos, junto con Deleuze y Guattari, ${ }^{30}$ una enfermedad psicológica individual («te voy a pagar un tratamiento psiquiátrico», amenaza Qüity — LVC:160— ), que una noción histórico-social que se desplaza entre dos polos: un delirio «paranoico» de 
dominación, que captura y codifica el deseo al remitirlo a algún centro del poder (estado, partido, iglesia, mercado); y otro «esquizo» que hace huir, crear, innovar, enamorarse: el delirio, en su forma profética, como «desbloqueo» de los flujos de deseo, buscando salidas en un socius poseado y socavado por corrientes e intensidades subterráneas de naturaleza cársica, agitándose sin cesar bajo las dominaciones, listas para subir a la superficie en los períodos de crisis.

De hecho, Cleo presagia en la carta en la que se despide de Qüity un giro rústico, propio de las modernizaciones sin progreso del capitalismo neoliberal: ${ }^{31}$ "Primero se va a cortar la luz. Y no van a funcionar los celulares, ni las computadoras, ni Internet, ni los motores que suben el agua a los edificios, ni nada. La guerra contra el Islam nos va a dejar sin nafta y los autos abandonados nos van a dejar sin caminos. No va a haber shoppings ni televisión ni ninguna forma de comunicación... No va a haber remedios. Ni comida frizada» (LVC:155). Conectada a las fuerzas del futuro, a los espectros de la guerra civil global, Cleo augura que va a haber Posos en medio mundo, porque la precariedad no es la excepción sino la regla; y como a la crisis y el hambre le seguirá la guerra, los que sobrevivan van a necesitar no solo del consuelo de la Virgen y su inyección de esperanza, sino, a falta de un horizonte revolucionario, de los mismos saberes, ardides y prácticas de afirmación de la vulnerabilidad de la vida que ensayaron a pequeña escala los pobres de la villa como alternativa al terror económico del capitalismo global o a la reterritorialización del poder en torno a un nuevo líder.

Va a haber entonces Posos en medio mundo porque en las condiciones neoliberales de un capitalismo violento y agresivo, la precariedad inducida y la explotación de la inseguridad como modos de producción de subjetividad, como explica Isabell Lorey, se vuelven instrumento de gobierno y de control de cada vez más personas. Pero también va a haber Posos porque en medio de la catástrofe y en oposición a la pura victimización, surgen por todas partes nuevas constelaciones de vida compartida, nuevas islas de deseo construidas en torno a demandas no solo de igualdad, libertad y democracia, sino también, en la lógica del «realismo villero» (LVC:56), del bienestar y la felicidad social expresada por la estatua deforme de la Virgen, raquítica y cabezona, afirmando en el desproporcionado tamaño de su cabeza «la esperanza de los pobres» (56).

Excavando pozos en todos lados para ver y oír lo que yace debajo — vastas acumulaciones de ser social sedimentado-, Cleo es una vidente y una oyente que va reinventando la historia y la geografía de un pueblo por venir, esto es, de una posibilidad de vida que solo la lengua emputecida del delirio hace posible: una posibilidad de vida, anclada en la materialidad de los cuerpos acéfalos de una multitud alegre y devota de una Virgen sin cabeza.

\section{Notas}

1 De aquí en adelante, salvo que se indique lo contrario, para citar La Virgen Cabeza, se abreviará LVC.

2 En torno a las catástrofes, Rebecca Solnit encuentra experiencias de reunión y de organización colectiva que rompen con la lógica de la privatización de lo común. La serie de catástrofes «naturales» que enumera Solnit se rompe cuando entre terremotos, inundaciones, tormentas de nieve, olas de

calor y huracanes, Solnit incluye «el colapso económico en la Argentina» (198), como si los estragos de una crisis económica fueran el resultado de fuerzas naturales incontrolables, o como si la escala en la que se miden las catástrofes políticas fuera la de la geología.

3 Hacer espacio, despejar: «el carácter destructivo no ve nada duradero», escribió Benjamin, que afirma la producción de 
escombros «no por los escombros mismos, sino por el camino que pasa a través de ellos» (161).

4 A propósito de la potencia colectiva de la multitud, ver Dardo Scavino (64-67).

5 Dice Gabriela Cabezón Cámara, en diálogo con Nora Domínguez: «En mis textos no hay patria, no hay un todo que dominar ni un todo que contenga, no hay una idea de pertenencia a una Nación. En todo caso habría clases, pero no se representan como universales en el sentido de que están contenidas en la situación que se relata, no tienen más referencias que las que se describen, los personajes no se sienten parte de algo mucho más grande o en todo caso les parece distante, otro planeta, la política es lo que se practica ahí en el lugar en el que están, es una escala pequeña, no pasa del tamaño de una villa». Ver Nora Domínguez (2014a:3).

6 Acerca de lo que Josefina Ludmer denomina «islas urbanas» en las literaturas del cambio de siglo y sus prácticas de producción y/o destrucción de la vida, con sus mecanismos naturalizadores y desdiferenciadores que igualan a los habitantes uniéndolos «por rasgos preindividuales, biológicos, postsubjetivos; por un fondo natural como la sangre, el sexo, la edad, las enfermedades o la muerte», ver Ludmer (133).

7 Acerca de la acción social de las referentes territoriales y sus performance de Eva Perón, ver Javier Auyero (153).

8 En una nota original de autor que acompaña «Evita vive», escribe Perlongher: «Estos textos juegan en torno a la literalidad de la consigna "Evita vive", haciendo aparecer a Evita "viviendo" situaciones conflictivas y marginales» (21-33).

9 Para Pilar Calveiro, el poder comunicacional es parte sustantiva de la nueva organización hegemónica, aunque, aclara, «no se trata en verdad de comunicación, sino de un proceso principalmente unidireccional (...). Se estructura desde puntos concentrados de emisión, buscando una penetración comunicativa [que] no deja espacio vacío, ni silencio; llena de ruido para poder simultáneamente extraer y vaciar. Para succionar toda vida y toda potencia, rellena con sus productos hasta las terminaciones capilares del sistema» (374).

10 Ver Maurizio Lazzaratto (2006:157).

11 Acerca de la construcción polifónica de La Virgen Cabeza, ver Carolina Ruiz.

12 Después de La Virgen Cabeza, Gabriela Cabezón Cámara explora explícitamente en Romance de la Negra Rubia los anudamientos que existen entre las formas que vienen de la protesta y del activismo político y las prácticas performáticas derivadas del arte contemporáneo. «Los míos», narra la Negra Rubia, «llamaron instalación a su campamento y performance a la vida que tuvieron que llevar ahí» (2014:19). A propósito de la relación entre la literatura de Cabezón Cámara y el arte contemporáneo, ver la tesis de Marina Ríos (141-233).

13 Dice Jens Andermann, en Tierras en trance a propósito de Deleuze y el trance como modalidad crítica del cine emergente del Tercer Mundo; «El trance es pues aquello que, en el mundo colonial, vuelve a ensamblar en el inconsciente, el espacio y tiempo del sujeto y la comunidad, escindidos por una violenta historia de desplazamientos y rupturas temporales» (2018:22).

14 Nora Domínguez sostiene que la poética de Cabezón Cámara conforma, en la tradición de la literatura nacional de la violencia, un «barroso feminista» (2013:145). Para una lectura de La Virgen Cabeza en el contexto de la obra de Cabezón Cámara, ver Nora Domínguez (2014b:23-29).

15 Acerca del descubrimiento de la individualidad para todos y del proyecto de colectividad libre como corazón de la emancipación obrera, ver Jacques Rancière (39).

16 Acerca de la existencia de los milagros y de su uso práctico por parte de charlatanes carismáticos, escribe César Aira en La mendiga: «A los milagros, se los diría decorativos, nada más. Pero tienen un uso práctico, y muy práctico: darle credibilidad al santón cuando acto seguido predica a favor de alguna práctico o alguna dieta, o lo que sea» (63).

17 La televisión opera un proceso inverso a la descentralización del mundo verbalmente ideológico de la novela (Lazzaratto, 2006:161).

18 Para la reconstrucción de la religiosidad popular a partir del choque entre los textos de la cultura escrita y la interpretación heterodoxa que los campesinos y artesanos de la Europa medieval hacían de ellos, ver Carlo Ginzburg.

$19 \mathrm{Al}$ personaje religioso del sacerdote, Deleuze y Guattari oponen el profeta: «El profeta no es un sacerdote. El profeta no sabe hablar, Dios le introduce las palabras en la boca: manducación de la palabra, semifagia de una nueva forma. El profeta, al contrario que el adivino, no interpreta nada: más que un delirio de idea o de imaginación, tiene un delirio de acción, una relación con Dios pasional y autoritaria, no despótica y significante; más que aplicar los poderes pasados y presentes, se anticipa y detecta las fuerzas del futuro» (1980:128-129). 
20 Acerca de la invención de formas económicas en la tradición autoorganizativa no estado-céntrica —un welfare desde abajo—, ver Verónica Gago.

21 Ver Anna Tsin (125).

22 Lamborghini, «El fiord», 22. Sigo a Gabriel Giorgi, que dice acerca de «El fiord» y la intersección entre el «animal» y el «pueblo» peronista: «Comer y coger: de eso estarán hechas, parece decir esta escritura, muchas luchas de la cultura y la política futuras. Allí ya están contenidas (...) las luchas que décadas después pondrán a piqueteros, travestis y prostitutas en el centro de las demandas democratizadoras reconfigurando los sentidos y los rostros de las luchas populares» (2014:181-182).

23 Fiesta, placer y sexualidad son inversiones utópicas de la matriz miserabilista del naturalismo. Dice Paola Cortés Rocca: «En esta trama barroca que hilvana miseria, diversión y sexualidad, en esta apertura de un campo de lo posible, la literatura no solo se aleja radicalmente del proyecto realista, sino que también se predispone a pensar lo subalterno como algo más que una mera víctima del neoliberalismo, sin ningún tipo de agencia» (229).

24 Acerca del ideal regulativo de género y de sexualidad implícito en el liderazgo carismático y su masculinidad heteronormativa, ver Negri y Hardt (11-12).

25 Dice Cecilia Palmeiro, a propósito de Néstor Perlongher y la construcción de una voz travestizada como máquina de guerra contra la tradición literaria y política: «El montaje de la voz conjugado con la lumpenización de la lengua (de allí que no se trate de una mera feminización), da como resultado el arma más violenta para la guerra de trincheras: una lengua emputecida». Ver Cecilia Palmeiro (27).

26 Ver Gastón Gordillo. Gordillo se propone «ver todas las ruinas, independientemente de su forma, como escombros» (25), para trazar una «historia de la creación, la destrucción y el silenciamiento de múltiples formas de escombros, y de las luchas por definir su significado y su legado afectivo» (314).

27 Ver Raúl Zibechi. Dice Zibechi que el territorio, en tanto creación político-cultural, es «el espacio donde se despliegan relaciones sociales diferentes a las capitalistas hegemónicas, aquellos lugares donde los colectivos pueden practicar modos de vida diferenciados» (31).

28 Para una crítica de la biopolítica como una concepción de poder blanda y «pacificada», indiferente a la guerra y a la guerra civil que se encuentra en la base del neoliberalismo — cuyo modelo es el Chile de Pinochet—, ver Maurizio Lazzaratto (2019).

29 Dice Nora Domínguez, en diálogo con Cabezón Cámara, que en la tradición literaria argentina, la muerte de un niño es un resto significante: «el puñado de huesitos del hijo de la cautiva, los niños enfermos por el contagio y la pobreza, los restos, los fetos. Son como lugares del sacrificio donde o a través de los cuales un "imaginario sexual nacional" persistente, como dijo María Moreno, se cobra con cuerpos infantiles sus abismos de significación» (2014a:5-6).

30 «Todo delirio es histórico-mundial, "desplazamiento de razas y de continentes"». Ver Gilles Deleuze (16).

31 Acerca de la urbanización desconectada de la industrialización del capitalismo neoliberal y la producción masiva de villas miseria, ver Mike Davis. La reestructuración de las economías del Tercer Mundo dirigida por el FMI produce modernizaciones sin progreso, dice David Harvey, quien compara el impacto de los planes de ajuste con los efectos devastadores de una catástrofe natural. Ver David Harvey.

\section{Referencias bibliográficas}

Agamben, G. (2014). El uso de los cuerpos. Buenos Aires: Adriana Hidalgo. Traducción de Rodrigo MolinaZavalía.

Aira, C. (1998). La mendiga. Buenos Aires: Mondadori.

Andermann, J. (2015). Nuevo Cine Argentino. Buenos Aires: Paidós. Traducción de Fermín Rodríguez. (2018). Tierras en trance. Arte y naturaleza después del paisaje. Santiago: Metales Pesados.

Auyero, J. (2001). La política de los pobres. Las prácticas clientelistas del peronismo. Buenos Aires: Manantial.

Benjamin, W. (1989). El carácter destructivo. Discursos interrumpidos I. Buenos Aires: Taurus, 157-163.

Traducción de Jesús Aguirre.

Cabezón Cámara, G. (2009). La Virgen Cabeza. Buenos Aires: Eterna Cadencia. 
(2014). Romance de la Negra Rubia. Buenos Aires: Eterna Cadencia.

Calveiro, P. (2006). Los usos políticos de la memoria. En AA. VV., Caetano, G. (Comp.). Sujetos sociales y nuevas formas de protesta en la historia reciente de América Latina. Buenos Aires: CLACSO, Consejo Latinoamericano de Ciencias Sociales, 359-382.

Cortés Rocca, P. (2018). Narrativas villeras. Relatos, acciones y utopías en el nuevo milenio. En Jitrik, N. (Dir.). Historia crítica de la literatura argentina. Tomo 12. Una literatura en aflicción, Jorge Monteleone, J. (Encargado del volumen). Buenos Aires: Emecé, 217-238.

Dardot, P. y Laval, Ch. (2014). Commun. Essai sur la révolution au XXI siècle. Paris: La Découverte.

Davis, M. (2007). Planet of Slums. New York: Verso.

Deleuze, G. (1996). La literatura y la vida. Crítica y clínica. Barcelona: Anagrama, 11-18. Traducción de Thomas Kauf.

Deleuze, G. y Guattari, F. (1980). Sobre algunos regímenes de signos. Mil mesetas. Valencia: Pre-textos, 117-153. Traducción de Thomas Kauf.

Domínguez, N. (2013). Movimientos ficcionales y no ficcionales de la violencia. Crímenes de mujeres. Aletria, 23(1), 137-147.

(2014a). Conversaciones y reenvíos con Gabriela Cabezón Cámara. Cuadernos LIRICO, (10). www. lirico.revues.org/ 1653

(2014b). La trilogía de Gabriela Cabezón Cámara: entre el enclave formal y la sedición de los cuerpos. Boletín de la Biblioteca del Congreso Nacional, (128), 23-29.

Gago, V.(2014). La razón neoliberal. Economías barrocas y pragmática popular. Buenos Aires: Tinta Limón.

Ginzburg, C. (1999). El queso y los gusanos. El cosmos, según un molinero del siglo XVI. Barcelona: Muchnik. Traducción de Francisco Martín.

Giorgi, G. (2014). Formas comunes. Animalidad, cultura, biopolítica. Eterna Cadencia.

(2017). Ocupación El Fiord. Ensayos sobre la ópera El Fiord. Caja muda, (9), 40-45.
(2018). La literatura y el odio. Escrituras públicas y guerras de subjetividad. Revista Transas, (3). http://www.revistatransas.com/2018/03/29/la-literatura-y-el-odio-escrituras-publicas-y-guerras-desubjetividad/

Gordillo, G. (2018). Escombros del progreso. Ciudades perdidas, estaciones abandonadas y deforestaciones en el norte argentino. Buenos Aires: Siglo XXI. Traducción de Fermín Rodríguez.

Harvey, D. (2005). A Brief History of Neoliberalism. New York: Oxford UP.

Jiménez, P. (2009, 10 de julio). Cabecita loca. Página 12. Suplemento SOY. https://www.pagina12.com.ar/ diario/suplementos/soy/1-861-2009-07-10.html

Lazzaratto, M. (2006). Política del acontecimiento. Buenos Aires: Tinta Limón. Traducción de Pablo Rodríguez.

(2019). Le capital déteste tout le monde. Fascisme ou révolution. Paris: Ámsterdam.

Lorey, I. (2015). State of Insecurity. Government of the Prearious. London, New York: Verso. Traducción de Aileen Derieg.

Ludmer, J. (2010). Aquí América Latina. Buenos Aires: Eterna Cadencia.

Merleau-Ponty, M. (1994). La fenomenología de la percepción. Barcelona, Planeta.

Negri, A. y Hardt, M. (2017). Assembly. New York: Oxford UP.

Palmeiro, C. (2010). Desbunde y felicidad. Buenos Aires: Título.

Perlongher, N. (2009). Evita vive y otros relatos. Cangi, A. (Ed. y Pról.). Buenos Aires: Santiago Arcos.

Rancière, J. (2010). Las paradojas del arte político. El espectador emancipado. Buenos Aires: Manantial, 9-28. 
Rozitchner, L. (2015). La violencia neoliberal del mercado. Escritos políticos. Buenos Aires: Biblioteca Nacional, 379-384.

Ruiz, C. (2017). Cuerpos y literatura disidente. La Virgen Cabeza, de Gabriela Cabezón Cámara. Badebec, 6(12), $352-365$

Scavino, D. (1999). La era de la desolación. Ética y moral en la Argentina de fin de siglo. Buenos Aires: Manantial.

Ríos, M. (2018). Figuraciones del arte en narraciones contemporáneas de César Aira, Diamela Eltit, Mario Bellatin, Gabriela Cabezón Cámara e Iñaki Echeverría. Tesis de Doctorado, Universidad de Buenos Aires, 141-233. www.repositorio.filo.uba.ar/bitstream/handle/filodigital/10019/uba_ffyl_t_2018_45814. pdf?sequence $=1$ \&isAllowed $=\mathrm{y}$

Solnit, R. (2010). A Paradise Built in Hell. The Extraordinary Communities That Arise in Disaster. New York: Penguin.

Tsin, A. (2015). The Mushroom at the End of the World. On the Possibility of Life in Capitalist Ruins. Princeton: Princeton UP.

Zibechi, R. (2008). Territorios en resistencia: cartografía política de las periferias urbanas latinoamericanas. Buenos Aires: Lavaca. 